\title{
Life cycle analysis of concrete and asphalt used in road pavements
}

\author{
Jocelyn lvel $^{1}$, Rachel Watson ${ }^{1}$, Bassim Abbassi ${ }^{1}$, Ziad Salem Abu-Hamatteh ${ }^{+}$ \\ ${ }^{1}$ School of Engineering, University of Guelph, Guelph, Ontario, N1G 2W1, Canada \\ ${ }^{2}$ Civil Engineering Department, Faculty of Engineering Technology, Al-Balqa Applied University, Amman 11134, Jordan
}

\begin{abstract}
The article examines the impact differences between producing concrete and asphalt. Both materials are widely used in the construction industry. Construction activities account for a large portion of greenhouse gases. Therefore, it is important to consider the Life Cycle Analysis (LCA) to reduce environmental impacts. In this study, the material processes were inputted into an LCA program called SimaPro. The database used for the study was Ecoinvent as it is one of the major databases within SimaPro. The materials were compared against impacts per kg of material produced as the functional unit. Each process was created using the materials, energy and transportation required to produce the materials. Waste streams were also included in the process to determine the impacts after the product was done with its useful life. Using the ReCiPe method, an LCA was conducted. Midpoint and endpoint categories were examined for both the productions. The processes had similar results for the human health and ecosystems categories; however asphalt was marginally higher for both. Asphalt had exceeded concrete in the resource impact category by $100 \mathrm{mPt}$. The results indicate that concrete is the more sustainable building material. Determination of various impacts of the materials is important for material selection.
\end{abstract}

Keywords: Asphalt, Concrete, Environmental impacts, Life cycle analysis, ReCiPe, SimaPro

\section{Introduction}

Life Cycle Analysis (LCA) studies are becoming increasing popular as pollution becomes a greater concern to the public. LCA studies analyze the impacts a product has on different aspects of the environment from the time it is produced to the disposal of it. This system life span is called the cradle to grave approach. This aspect of LCA is important as it not only looks at the impacts that are generated to produce a product, but also takes into consideration the use and how the product is disposed of at the end of its useful life [1].

Construction is a major contributor to global greenhouse gas emissions [2]. Two very common construction materials are concrete and asphalt. Both materials can be used for the construction of roadways, parking lots, sidewalks and recreational facilities. The purpose of this paper is to compare the two products using LCA approach. LCA is a methodology for analyzing and evaluating processes and products in regards to the environmental load they pose over their entire life, from cradle to grave [3]. The LCA software, SimaPro, will be used to determine the impacts each material have on the environment through production and disposal. With the increase in demand on the construction industry due to a rapidly expanding global population, making sustainable decisions when it comes to building materials is extremely important. Both concrete and asphalt contribute environmental burdens, such as release of carbon dioxide, at various stages of their life. Therefore, in order to make sustainable decisions, it is important to study and compare the entire life cycle of each material.

Concrete is one of the most widely used building materials, with a global usage of approximately 25 gigatonnes per year [2]. Concrete production is responsible for more than five percent of human induced carbon dioxide emissions annually [2]. The majority of these emissions are attributed to the creation of the cement that goes into making the concrete, which is a very energy intensive process [2]. LCA assessments on concrete have grown in popularity due to its large impact on the environment. Gursel et al. [2] compared various LCA studies that had been conducted on concrete production. The three main findings they reported from their review was that there is a lack of LCA knowledge on the toxic emissions
This is an Open Access article distributed under the terms of the Creative Commons Attribution Non-Commercial License (http://creativecommons.org/licenses/by-nc/3.0/) which permits unrestricted non-commercial use, distribution, and reproduction in any medium, provided the original work is properly cited.

Copyright (C) 2020 Korean Society of Environmental Engineers
Received November 13, 2018 Accepted January 30, 2019

${ }^{\dagger}$ Corresponding author

Email: hamatteh@bau.edu.jo

Tel: +962-777-484-772

ORCID: 0000-0003-0929-1011 
from manufacturing, there is a lack of variation between technologies used and that neglecting small energy uses could be impactful when applied on a global scale [2]. Concrete LCA is most commonly conducted for a small range of products and input materials, therefore previous conducted studies are difficult to apply to situations around the world [2].

Asphalt is another common building material used in the construction industry. In 2015, the global demand of asphalt was predicted to be 119.5 million tonnes per year ( 0.1195 gigatonnes per year) [4]. A substantial amount of greenhouse gas emissions and air pollutants result from the production of asphalt due to the very high temperatures required in production [1].

Various studies have been conducted to compare the use of concrete and asphalt in construction. Kucukvar et al. [5] used an ecologically-based LCA model to compare continuously reinforced concrete (CRCP) and hot-mix asphalt (HMA). This model differs from typical LCA approaches as it broadened the system boundary to include ecological goods and services in addition to the national economy typically considered [5]. The Life Cycle Inventory (LCI) information gathered was based on the functional unit of $1 \mathrm{~km}$ of both products used for road construction. The study found that CRCP is the more sustainable choice when total ecological resource consumption is included in the study, however HMA is better for industrial energy utilization [5]. Similarly, to other studies conducted, they also determined that cement manufacturing consumed the most energy and released the most carbon dioxide when analyzing the production of concrete [5].

This study will focus on the production of asphalt and concrete and analyze their midpoint and endpoint impacts. An additional LCA was conducted that included waste disposal methods for both products. The focus of this study is to determine whether concrete or asphalt is a more sustainable construction material. The paper begins by defining the goal and scope of the LCA study. The LCI process is then described, indicating all input parameters and how they were determined. The Life Cycle Impact Assessment (LCIA) is then conducted, which interprets the results obtained from SimaPro. Conclusions and recommendations to further the study are then made. This report follows the documentation as prescribed by the ISO $14040 / 14044$.

\section{Discussion and Results}

The overall goal of the LCA study was to compare the difference in impacts that the production of concrete and asphalt create. The functional unit for this study was set as impacts per kg of material produced. In order to achieve results that help represent the functional unit, the amount of material produced was set to one $\mathrm{kg}$ for both the concrete and asphalt. Both materials are used for construction purposes and can be used interchangeably for many projects. The goal of this study is to ultimately determine the more environmental friendly per one $\mathrm{kg}$ of material. The boundaries of the system in the study will be limited to the production of the material and the disposal of the material. The study will not include the use or impacts during the life span of the products. The materials and energy inputted to create the product and landfill effects of the materials were the boundaries of the study.
The study will be modeled on SimaPro to determine accurate results. Each process will include not only the material that it comprises of, but also the required energy and transportation will also be included. This is to expand the scope of the study to achieve more insightful results. The waste streams will also be included into the processes to achieve a cradle to grave approach. This is important in LCA studies because the concerns of product's impacts are not only found in the process stage, but also throughout their entire life span including how they will be disposed of. The study will be completed as a system process as this will provide an overall process impact rather than the specific unit process.

\subsection{The Assessment Method}

The assessment method used in SimaPro was the ReCiPe endpoint method. This method was chosen as it provides single scores that create similar comparison between the concrete and the asphalt materials. The ReCiPe method separates the results into two impact categories and provides indicator scores to express the severity of the environmental impacts [6]. The two impact categories in the ReCiPe method are the midpoint and the endpoint impacts which both will be analyzed in this study. Midpoint impacts are described as more specific and have a higher level of scientific data in the results [7]. The midpoint impacts include issues with climate change, human toxicity, ozone layer depletion, acidification and abiotic resources depletion [1]. Endpoint impacts are more focused on the damages that occur from the production of the product in question. The endpoints are typically elements that the public thinks are worthy of protection [7]. The endpoint impact results use the midpoint categories to assess the different types of damages into three categories. The endpoint impacts take into consideration damages to human health, ecosystem health and resource availability [1]. Both the endpoint and the midpoint impact results were taken into consideration for this project to determine the different types of impacts each of the materials are creating.

\subsection{Life Cycle Inventory}

In order to determine the life cycle impacts of the concrete and asphalt the inventory was to be defined. SimaPro was used to analyze the two different types of material in an efficient way. The database used in SimaPro was Ecoinvent, as this database has many options for global information. To produce more accurate results, the composition of each of the materials was found through creditable sources and then entered into SimaPro. To create a simple comparison between the concrete and the asphalt, the amount of product produced was set to $1 \mathrm{~kg}$ and the composition materials were assigned accordingly.

The composition of concrete is Portland cement, aggregates, water, air and sand [8]. The Portland cement was found as its own item within the Ecoinvent database. In the description of the Portland cement, it stated that all production, energy use and transportation prior to its use were included in the process. For the cement, it was assumed that no other processes were needed to make up the composition of the cement. The aggregate material was broken down further as Ecoinvent did not have an option for aggregate. Through further research it was found that the ideal mixture for the concrete aggregate was crushed gravel and sand [8]. 


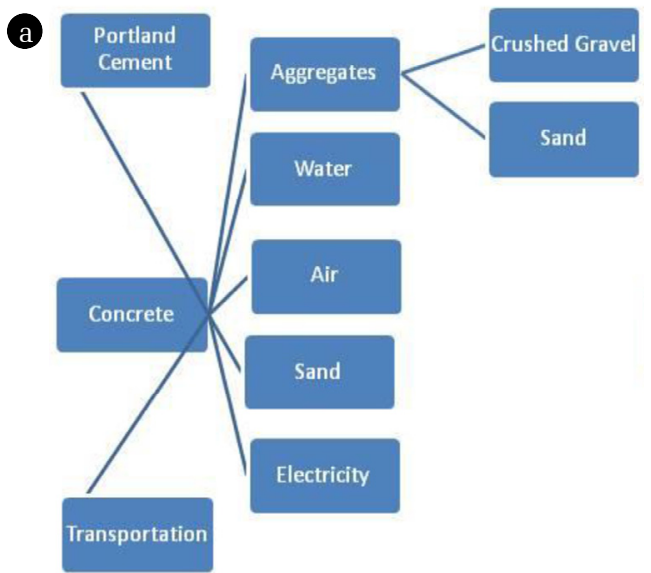

Fig. 1. Process flow diagram for (a) concrete and (b) asphalt.

The aggregate was then broken down in SimaPro into crushed gravel and sand as they were both options within the Ecoinvent database. For the last three items of the concrete mixture, water air and sand were all inserted as inputs from nature into the concrete production process. The ratios of each input were; $6 \%$ air, $11 \%$ Portland cement, $41 \%$ aggregate, $26 \%$ sand and $16 \%$ water [8]. The final addition to the concrete process was electricity. Energy is needed to mix the materials to get the final product. A low voltage option within the Ecoinvent database was chosen as it was assumed that the mixer would be relatively small. The transportation of the material was also taken into consideration. It was assumed that the material would be transported on a truck by road over $100 \mathrm{~km}$. Therefore, in SimaPro, to produce $1 \mathrm{~kg}$ of concrete, $0.1 \mathrm{tkm}$ was inputted. Fig. 1(a) displays a visual image of the process created in SimaPro.

After the concrete process was defined in SimaPro, asphalt production was investigated. The Ecoinvent database was used again for the asphalt process. From research, it was found that asphalt was composed of aggregates and asphalt cement [9]. The aggregate item was taken as the same aggregate material created in the concrete process, as they are both comprised of crushed gravel and sand. Asphalt pavement was modeled as a combination of 95\% aggregate bound together by asphalt cement. The asphalt cement was determined to be a mixture of $99 \%$ bitumen and $1 \%$ sulfur [10]. Bitumen [11] is defined as the liquid binder that holds materials together [11]. In the Ecoinvent database there is a heated bitumen option that includes all production of the material and the heating to mix with other materials. This option was assumed to be sufficient with no further processes defined. The key difference in production between the concrete and the asphalt was that the asphalt mixture must be heated to achieve the best properties. Thus, it was important to choose an option within the database that included the heating of the binder material. Therefore, for the asphalt cement the heated bitumen was defined as a material input. Sulfur was an additional item needed for the asphalt cement, and was inputted as a natural resource. In the actual asphalt process within SimaPro both the asphalt cement and the aggregate processes were defined as material inputs. Electricity and transportation were also considered in the asphalt process. Both inputs were considered the same as they were in the concrete process. The electricity was kept the same

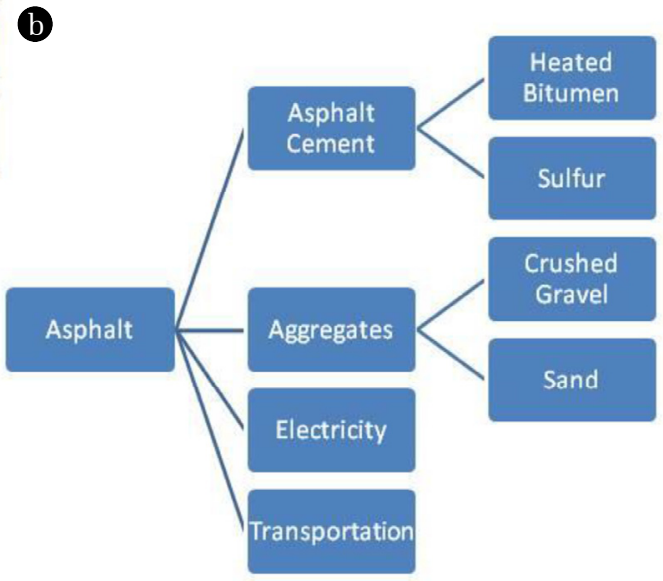

because it was desired that the scale at which the material is being produced was kept the same. The transportation was kept the same at $0.1 \mathrm{tkm}$ as well to determine the impacts of travelling the same distance with the different materials. Fig. 1(b) displays the visual image of the final asphalt production process.

To account for the disposal of each of the materials, waste streams were created in SimaPro. For the concrete process a waste stream entitled "concrete waste" was chosen as it included all the processes and emissions that occur when concrete is land filled. This process fit within the goals of the project as it provided impact details after the end of life of the material. For the asphalt process the waste stream of "asphalt waste" was chosen as it also included all the emissions and products once the asphalt was land filled. The waste streams were important in the LCA as this provided all impacts from cradle to grave for each process analyzed.

\subsection{Life Cycle Impact Assessment}

\subsubsection{Concrete results}

The following figures display the results produced by SimaPro from the concrete production analysis. Fig. 2(a) shows the process network, which gives a visual representation of the processes that go into the production, and the resulting impact that they create. Using the ReCiPe method, impacts are reported in points (Pt), which indicates the total environmental load as expressed as a single score [12]. The electricity required for mixing the concrete has the highest impact, at $0.0694 \mathrm{Pt}$ out of the total $0.08 \mathrm{Pt}$. The next is the production of Portland cement at 0.00809 Pt. The majority of the literature reviewed reported that Portland cement typically contributes the most impact in concrete production [1, 13]. When electricity is taken out of the analysis, this is the case for this LCA scenario, however it was determined that electricity was an important addition to the study and could not be neglected. Electricity's high impact could be attributed to the assumption that $1 \mathrm{kWh}$ is required to power the motor that would mix the cement.

Conducting an LCIA, two different methods can be used to analyze the results; midpoint and endpoint. Midpoint results quantify the problem-oriented impacts, where endpoint quantifies the damage oriented impacts associated with the process [3]. Fig. 3 displays the midpoint results. Midpoint impacts asses the emissions or 

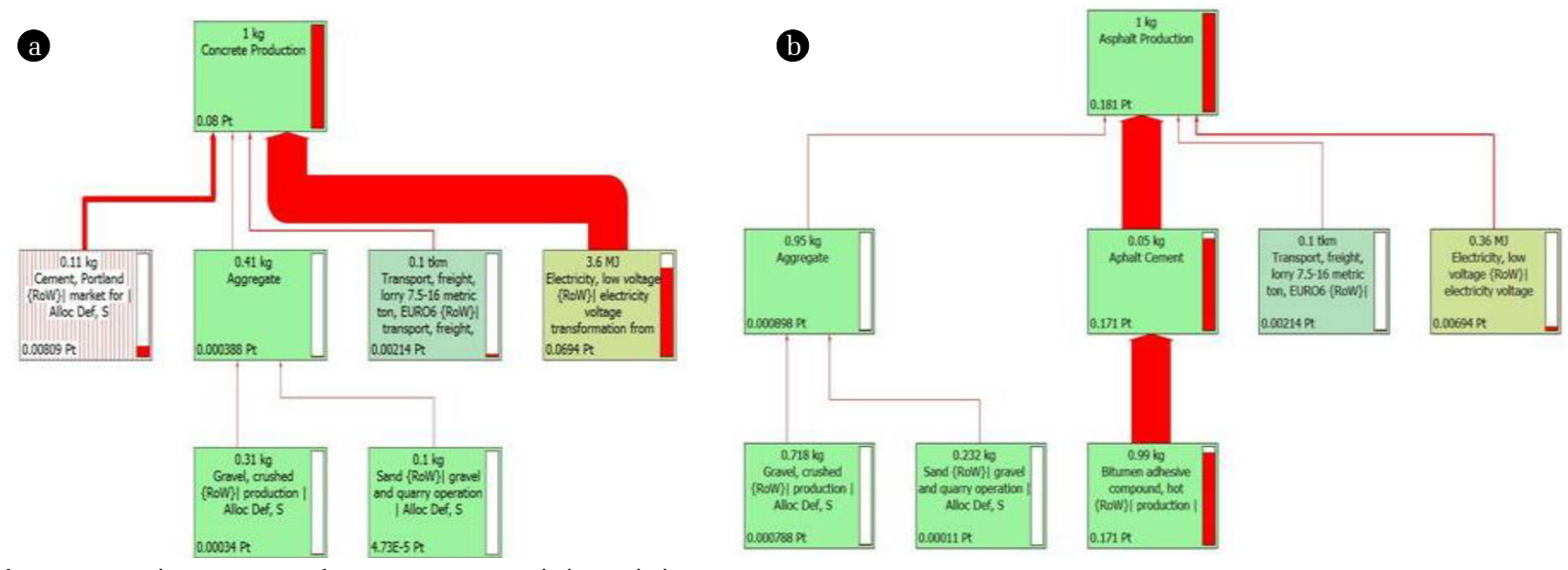

Fig. 2. Network in SimaPro for (a) concrete and (b) asphalt.

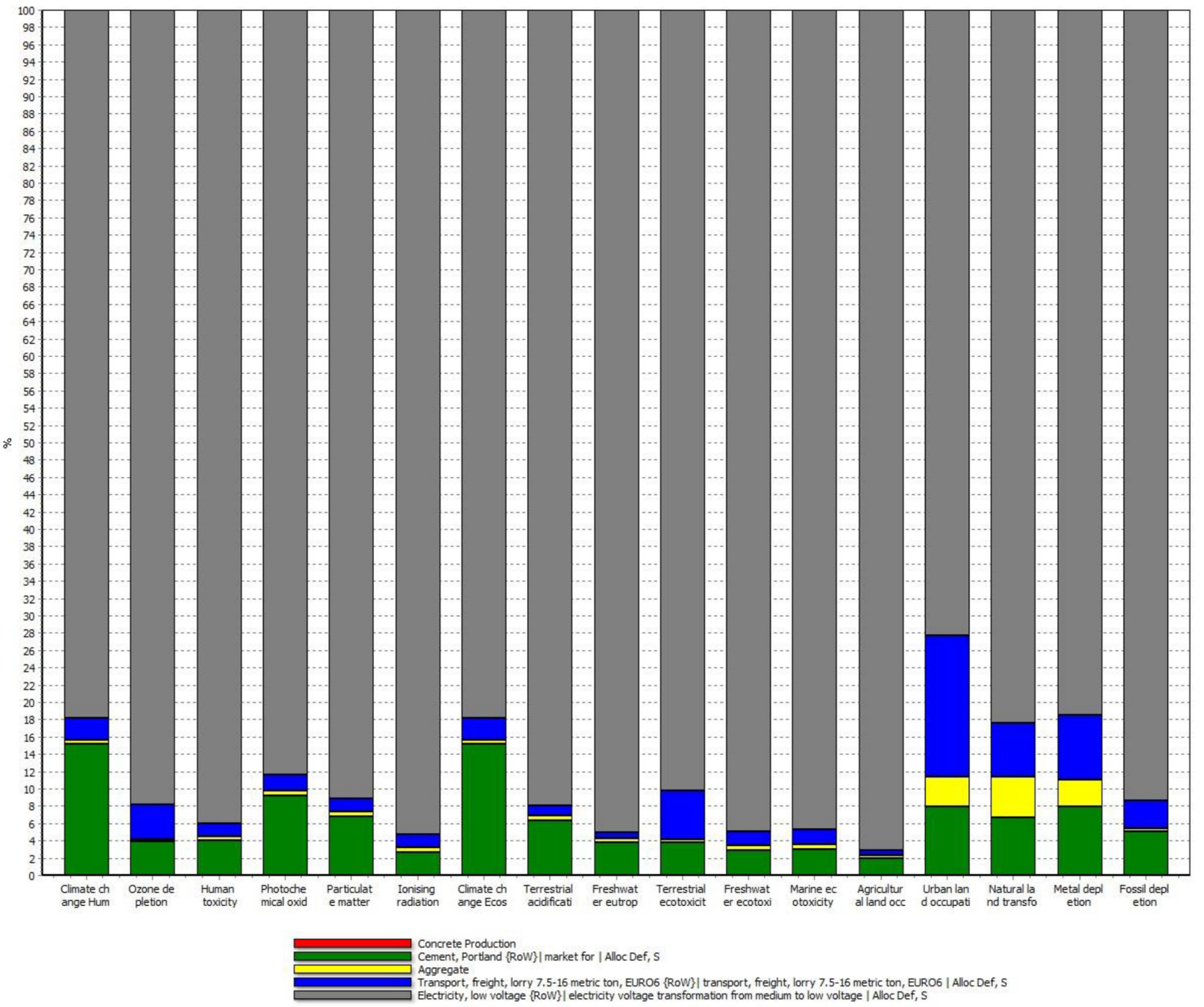

Analyzing $1 \mathrm{~kg}$ 'Concrete Production'

Fig. 3. Midpoint results for concrete. 


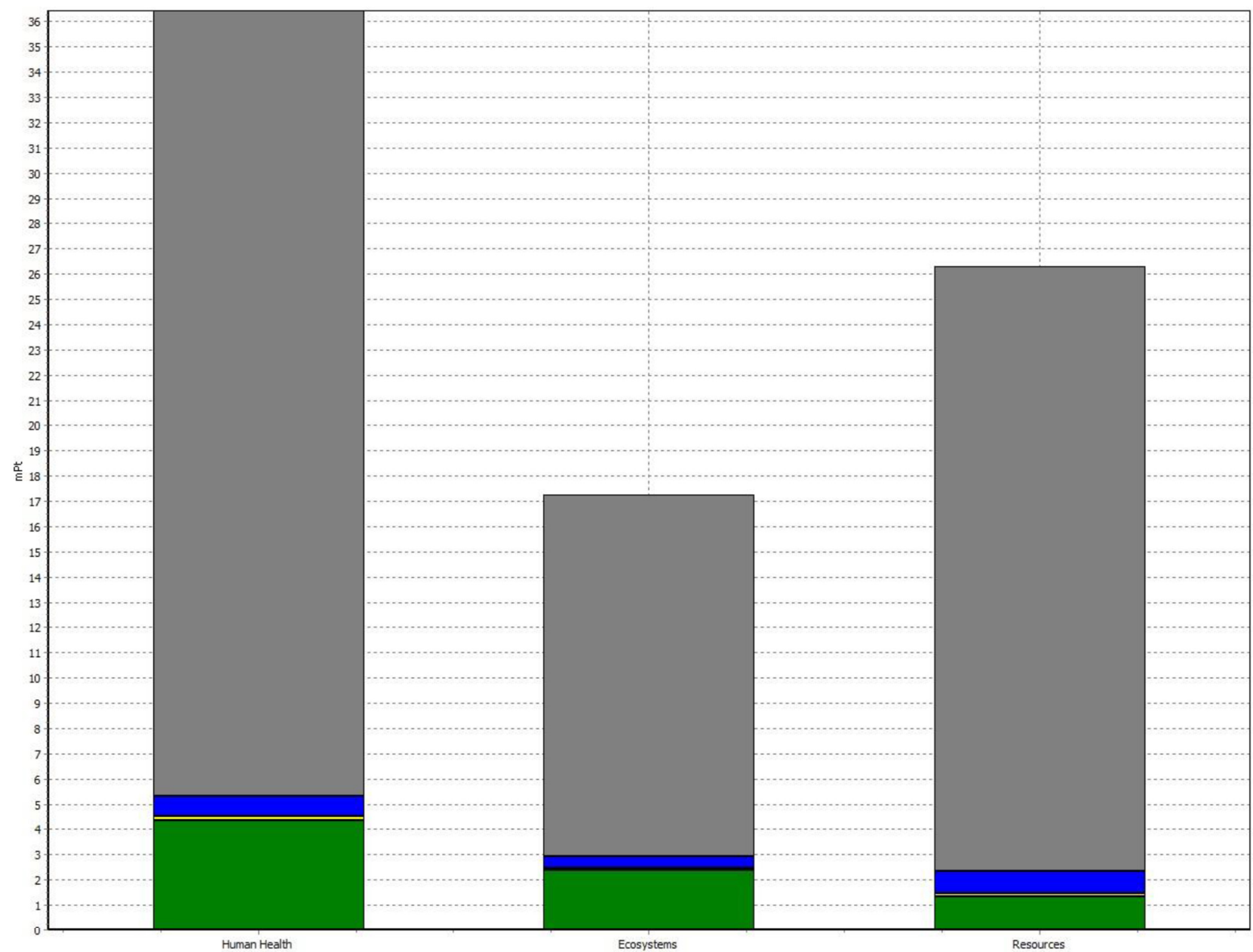

Concrete Production

Concrete Production
Cement, Portand \{RoW\}| market for | Alloc Def, S

Cement, Por

Transport, freight, lorry 7.5-16 metric ton, EURO6 \{RoW\}| transport, freight, lorry 7.5-16 metric ton, EURO6 | Alloc Def, S

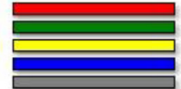

Electricity, low voltage $\{$ RoW\}

Analyzing $1 \mathrm{~kg}$ 'Concrete Production';

Method: ReCiPe Endpoint $(H)$ V1.11 / Europe ReCiPe H/A / Weighting

Fig. 4. Endpoint results for concrete.

extraction of the particular item defined in the inventory assessment and determines its importance on the impact categories [1]. The impact categories included in this study are listed in Fig. 3 and Fig. 4 displays the endpoint results. Endpoint methodologies use the midpoint impacts to assess damage on human health, ecosystem and resource depletion. The midpoints are associated to the endpoint damage categories to determine the weighting for each of the three endpoint indicators [1].

The midpoint analysis in Fig. 3 shows that electricity has the most impact on all midpoint categories. It has the highest effect on agricultural land at $97 \%$. Portland cement has the second highest impact in all categories. Its highest impact is on both climate change human and climate change ecosystem at $15 \%$. Transportation shows significant impact on urban land occupants, natural land transformations and metal depletion. Aggregate shows insignificant con- tribution to all categories.

Fig. 4 contains the endpoint analysis. The highest points from the production of concrete are attributed to human health, which indicates that concrete has the most impact on human health due to the midpoint impacts assessed. Again electricity is the biggest contributor, followed by Portland cement production, transportation and lastly aggregate.

\subsubsection{Asphalt results}

The following figures display the results complied from the LCA analysis conducted on SimaPro for the production of asphalt. Fig. 2(b) displays the process network, which gives a visual representation of the weight each input contributes to the overall production. Asphalt cement has the largest impact from production, contributing 0.171 Pt out of the total 0.191 Pt from the complete production. 


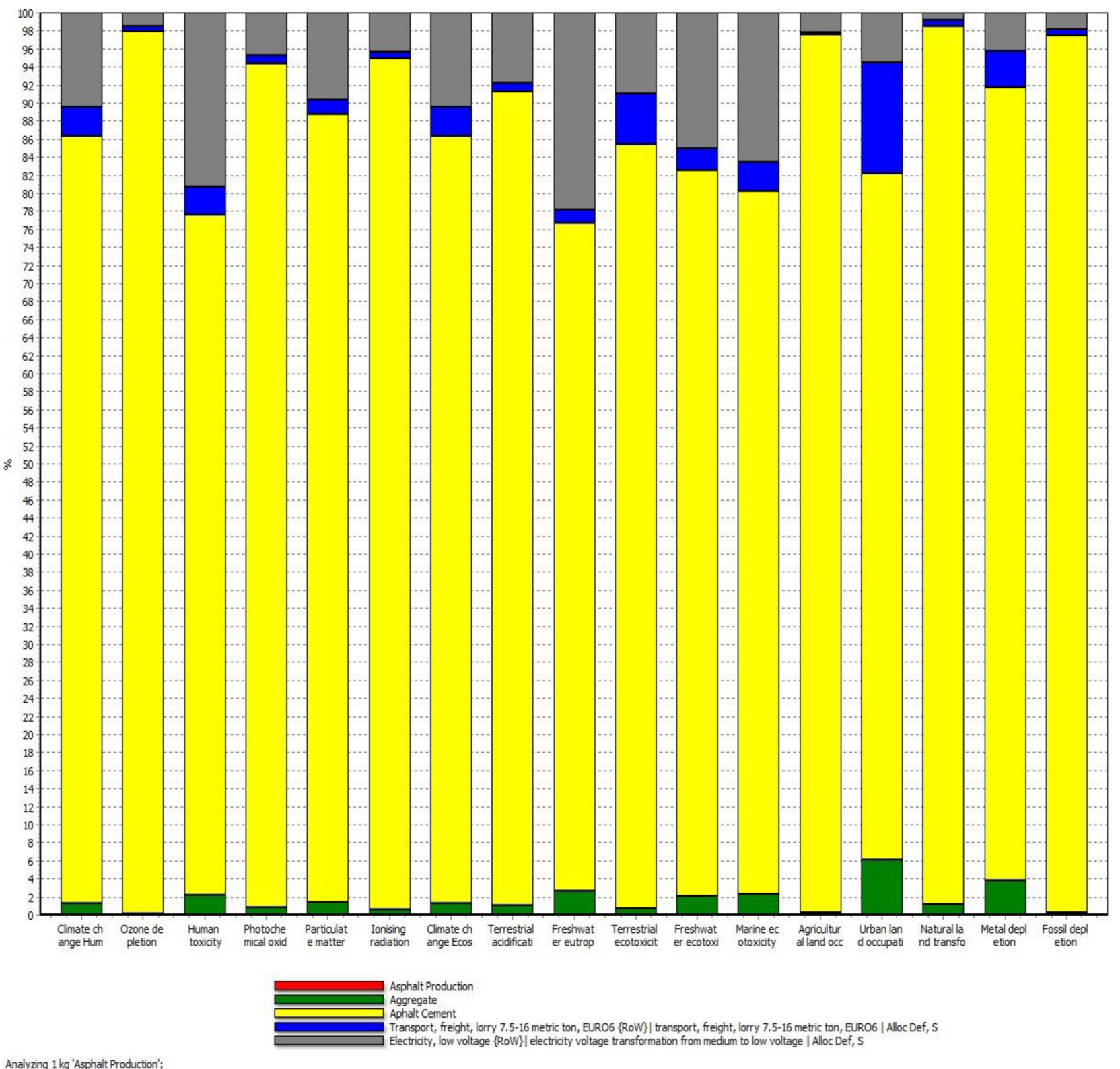

Analyzing $1 \mathrm{~kg}$ 'Asphalt Production';
Method: ReCPe Endpoint (-) V1.11 / Europe ReCiPe H/A / Characterization

Fig. 5. Midpoint results for asphalt.

This was expected, as asphalt cement contains bitumen which requires a very high temperature to be manufactured. This heating process creates many environmental impacts. The rest of the inputs contribute a much smaller impact as a result of the production.

Fig. 5 displays the midpoint results from the study. Asphalt cement has the highest contribution to each impact category. The highest contribution is to fossil fuel depletion at 97\%. Electricity contributes the highest impact at $74 \%$ to the freshwater eco-toxicity category. The next highest midpoint impact is from the electricity required to mix the asphalt. The midpoint impacts range from $2 \%$ to $22 \%$. Transportation has some effect on each category.
Aggregate has very little contribution to each impact category.

Fig. 6 displays the endpoint results from the production of asphalt. From this analysis, it is clear that asphalt cement poses the highest impact on resources. Approximately $130 \mathrm{mPt}$ imposed on the resource endpoint is a result of the production of asphalt cement. This result is intuitive as the creation of asphalt cement relies heavily on the extraction of natural resources such as sulfur. Bitumen makes up the highest percentage of asphalt cement. Bitumen is made up of petroleum which is processed from naturally occurring crude oil [11]. Extraction of crude oil creates a significant impact on natural resources which is reflected in the endpoint analysis. 


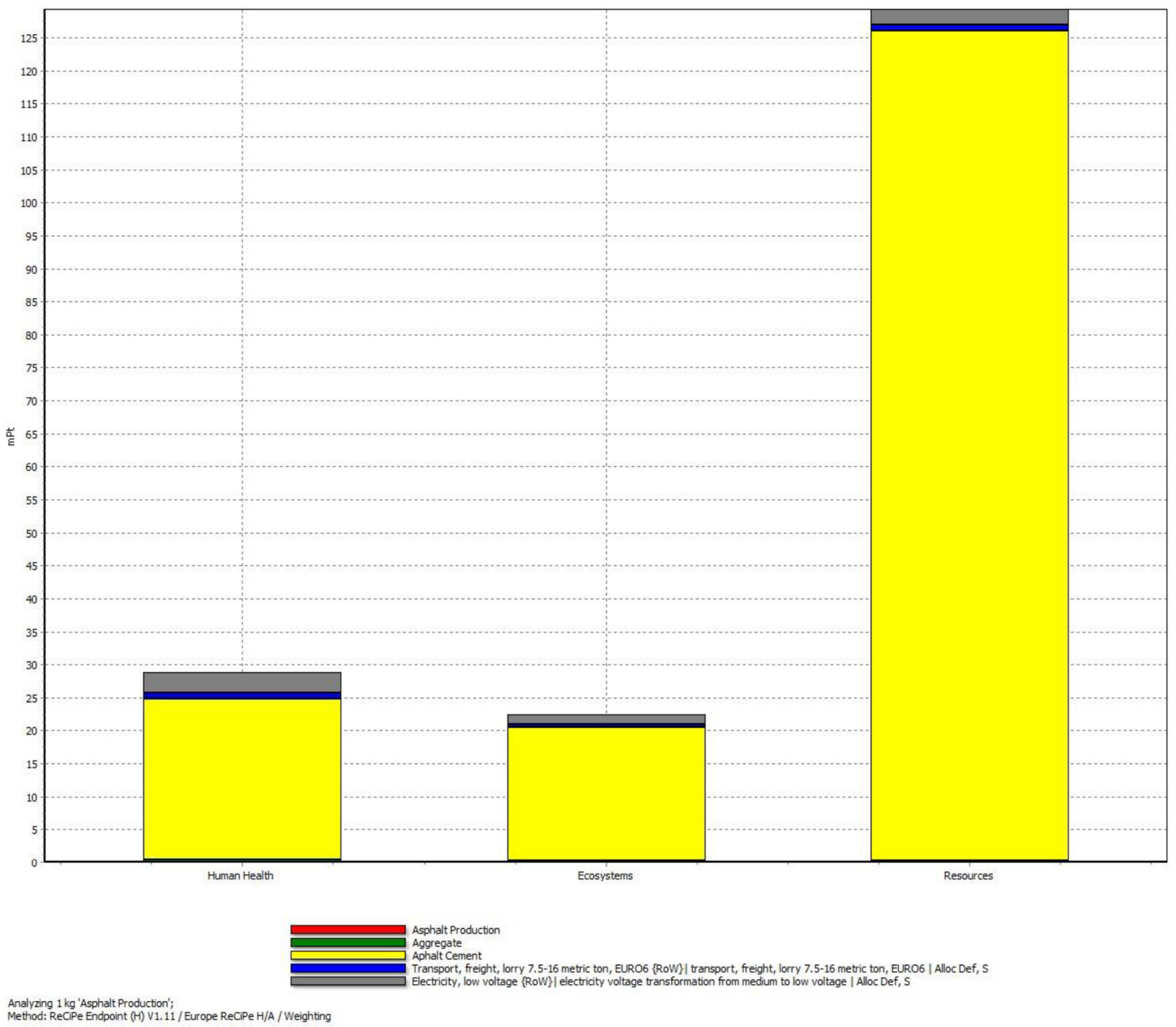

Fig. 6. Endpoint results for asphalt.

\subsubsection{Comparison}

The analysis of concrete resulted in a total of $0.08 \mathrm{Pt}$, where asphalt had a total of $0.181 \mathrm{Pt}$. This is a difference of $0.101 \mathrm{Pt}$, indicating that asphalt imposes the highest impact throughout its lifecycle on the environment. One similarity noted between the two studies was that aggregate has very little impact overall. The aggregate was assumed to be similar for both processes; therefore it made sense that they imposed a small impact for each. Aggregate was assumed to be composed of sand and gravel, which required no processing prior to the addition to either material mixture. Both studies also assumed to use $1 \mathrm{kWh}$ of electricity in production. They both resulted in a total of 0.0649 Pts contributing to each process. In concrete this was the largest contribution, however in asphalt this was an almost insignificant contribution compared to the $0.171 \mathrm{Pt}$ resulting from asphalt cement. Comparing the end- point analysis, it is clear that asphalt imposes a much greater risk on each category due to the production of asphalt cement. The total impacts for human health, eco systems and resources were $29 \mathrm{mPt}, 22 \mathrm{mPt}$ and $130 \mathrm{mPt}$ respectively for asphalt. The total impacts on human health, eco systems and resources were 37 $\mathrm{mPt}, 17.2 \mathrm{mPt}$ and $26.2 \mathrm{mPt}$, respectively for concrete. The impacts imposed on human health and ecosystems are somewhat comparable between the two processes, however the asphalt production is still higher in both cases. The impact on resources created from the production is almost $100 \mathrm{mPt}$ higher than the impact that concrete imposes. This analysis answers the question as to what is the more sustainable material to use for construction purposes in terms of an LCA study. It is shown that concrete is the more sustainable material.

Huang et al. [13] studied the development of a life cycle assess- 

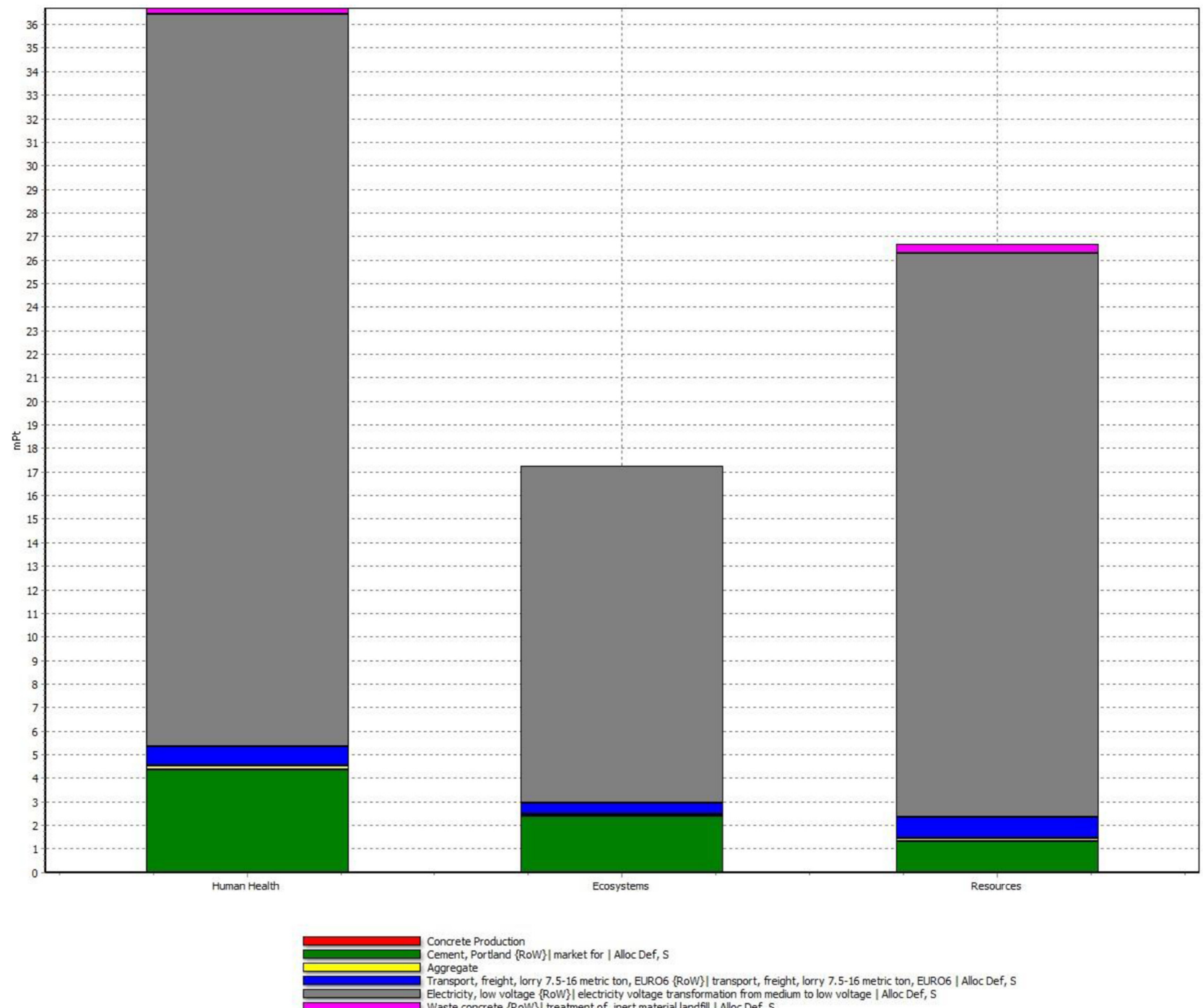

Analyzing $1 \mathrm{~kg}$ 'Concrete Production';
Method: ReCiPe Endpoint (H) V1.11/ Europe ReCiPe H/A / Weighting

Fig. 7. Endpoint results with waste scenario for concrete.

ment tool for construction and maintenance of asphalt pavements and concluded that the production of hot mix asphalt and bitumen was found to represent energy intensive processes. Blankendaal et al. [1] investigated the scenario of reducing the environmental impact of concrete and asphalt in order to measure and evaluate the environmental impact of concrete and asphalt. They used several composition scenarios for the materials. They emphasized that the evaluated concrete mixes show the highest potential for improvement through using alternative cement types. Moreover, this will lead to maximum reduction of $39 \%$ in environmental impact and the most substantial impact reduction in asphalt can be realized through application of warm-mix asphalt instead of hot mix asphalt [1].

\subsubsection{Waste scenario}

To further the LCA study, a waste scenario was added to both scenarios. Fig. 7 and 8 display the endpoint results for concrete and asphalt respectively as a result of the waste scenario addition. Each waste scenario changed the endpoint impacts minimally. This is because both materials can be recycled at the end of their useful life, making very little waste. The recycling of the materials does not impose significant impacts on human health, ecosystems or resources.

\subsubsection{Uncertainties}

With every LCA study there are some uncertainties. The version of SimaPro that was used to complete the project does not take into consideration the possible uncertainties that arise with the study. Although they are not directly stated or shown through the results, it is important to keep in mind that there could possibly be error. An uncertainty could arise in many forms including the database items that were used in the study. The values could be generalized or not applicable to certain countries depending on 


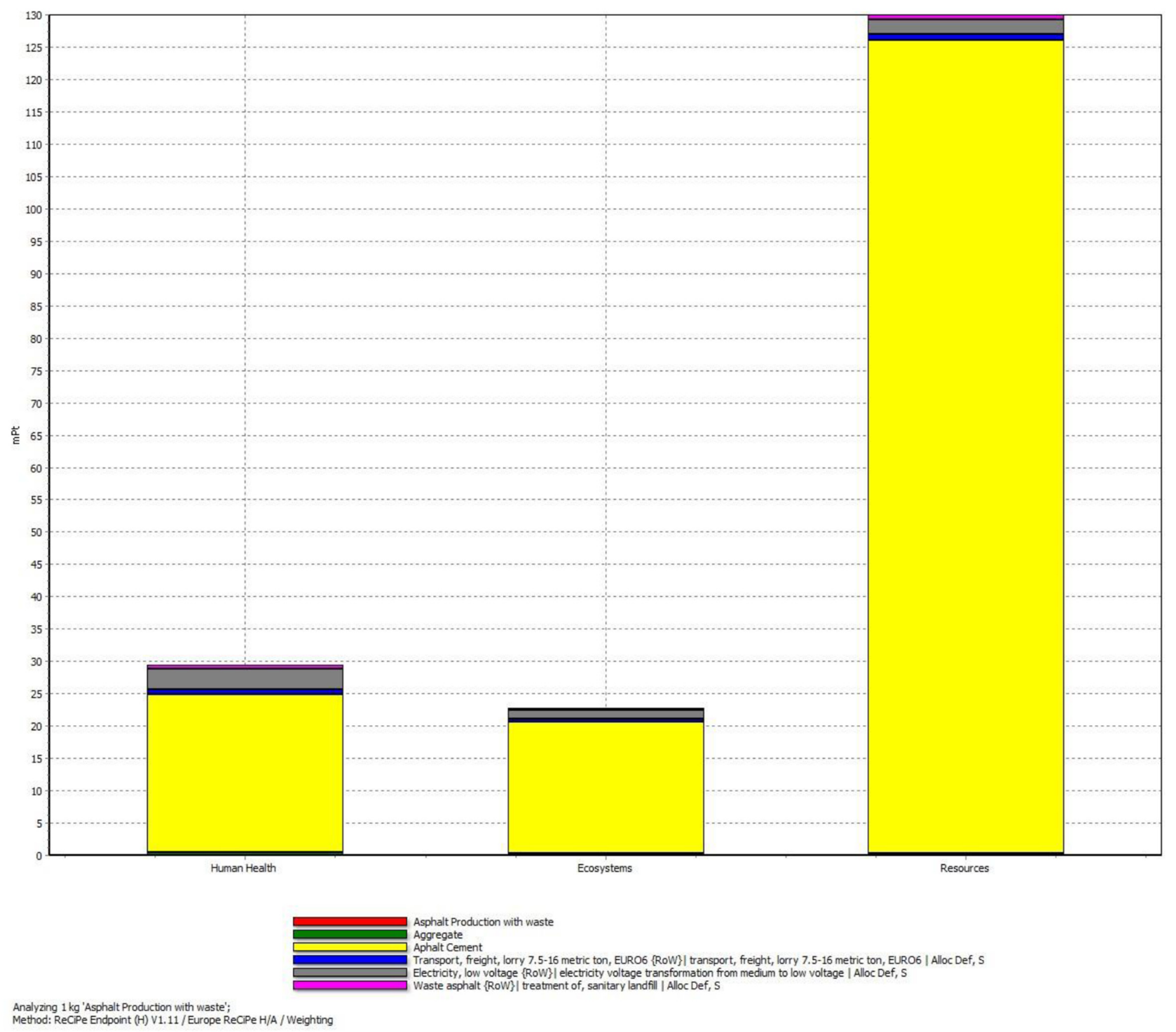

Fig. 8. Endpoint results with waste scenario for asphalt.

the option chosen. SimaPro is an excellent software tool to use for LCA studies; however uncertainty could arise with lack of knowledge of the program. One known uncertainty in SimaPro is through the endpoint impact results. The endpoint results are based off the harm that the midpoint impacts create. The resulting impacts typically have an unrealistic level of accuracy in comparison with the midpoint impacts [1].

\section{Conclusions}

In conclusion, an LCA study was completed on the difference between the construction materials of concrete and asphalt. The analysis was completed on SimaPro using the Ecoinvent database. Both materials were defined to $1 \mathrm{~kg}$, both including the same elec- tricity required for mixing and the same transportation distance. Through research, the composition of both materials were determined and inserted into SimaPro. Following the ISO 14040/14044 standards the LCA was completed. Using the ReCiPe method on SimaPro, an LCIA was conducted. Midpoint and endpoint categories were examined for the production of both asphalt and cement. The midpoint analysis for concrete revealed that the use of electricity for mixing posed the highest impact on each category. The midpoint analysis for asphalt revealed that the creation of asphalt cement posed the highest impact on each category. The endpoint analyses were compared for both products. Overall, both processes had similar results for the human health and ecosystems categories; however asphalt was marginally higher for both. Asphalt had exceeded concrete in the resource impact category by $100 \mathrm{mPt}$. This lead to the conclusion that concrete is the more sustainable building 
material. To further the study, waste scenarios were added to each process. This revealed little change on the endpoint analyses for both products and did not change the overall conclusion that concrete more sustainable. The study successfully revealed that concrete is the more sustainable construction product, when compared to asphalt.

\section{References}

1. Blankendaal T, Schuur P, Voordijk H. Reducing the environmental impact of concrete and asphalt: A scenario approach. J. Clean. Prod. 2014;66:27-36.

2. Gursel A, Masanet E, Horvath A, Stadel A. Life-cycle inventory analysis of concrete production: A critical review. Cement Concrete Comp. 2014;51:38-48.

3. Ortiz O, Castells F, Sonnemann G. Sustainability in the construction industry: A review of recent developments based on LCA. Constr. Build. Mater. 2009;23:28-39.

4. World Highways. Study predicts world asphalt demand to approach 120 million tonnes by 2015 [Internet]. World Highways; [cited 1 March 2012] Available from: http:/www.worldhighways. com/categories/materials-production-supply/news/study-predicts-world-asphalt-demand-to-approach-120million-tonnesby-2015/.

5. Kucukvar M, Tatari O. Ecologically based hybrid life cycle analysis of continuously reinforced concrete and hot-mix asphalt pavements. Transport. Res. D 2012;17:86-90.

6. Goedkoop J, Heijungs R, Huijbregts M, De Schryver A, Struijs J, Van Zelm R. ReCiPe 2008: A life cycle impact assessment method which comprises harmonised category indicators at the midpoint and the endpoint level [Internet]. c2008 [cited 6 January 2009]. Available from: https://www.rivm.nl/sites/default/files/2018-11/ReCiPe\%202008_A\%20lcia\%20method\%20which\%20comprises\%20harmonised\%20cate g o r y \% 20 ind i c a t or s \% 20 at \% 20 t he \% 20 m idpoint\%20and\%20the\%20endpoint\%20level_First\%20edition\%20Characterisation.pdf.

7. Bare JC, Gloria TP. Environmental impact assessment taxonomy providing comprehensive coverage of midpoints, endpoints, damages, and areas of protection. J. Clean. Prod. 2008;16:1021-1035.

8. PCA. How Concrete is made. PCA - America's Cement Manufacturers; c2017. Available from: http://www.cement.org/ cement-concrete-basics/how-concrete-is-made.

9. APA Michigan. What is hot mix asphalt [Internet]. Asphalt Pavement Association of Michigan; c2008. Available from: http://www.apa-mi.org/what_is_hot_mix_asphalt_paveme.php.

10. MCA. Asphalt cements - Penetration grade [Internet]. McAsphalt Industries Limited; c2015. Available from: http://www.mcasphalt.com/products/asphalt-cements.

11. Bitumina. What is bitumen [Internet]. Bitumina hi-tech pavement binders; c2014. Available from: http://www.bitumina. co.uk/whatisbitumen.html.

12. SimaPro Help Center. What does the unit "points" in ReCiPe mean and how is it determined? [Internet]. Available from: https://support.simapro.com/articles/FAQ/What-doesthe-unit-points-in-ReCiPe-mean-and-how-is-it-determined.

13. Huang Y, Bird R, Heidrich O. Development of a life cycle assessment tool for construction and maintenance of asphalt pavements. J. Clean. Prod. 2009;17:283-296. 